\title{
Subprodutos industriais na ensilagem de capim-elefante para cabras leiteiras: consumo, digestibilidade de nutrientes e produção de leite ${ }^{1}$
}

\section{Jobel Beserra de Oliveira ${ }^{2}$, Aureliano José Vieira Pires ${ }^{3,7}$, Gleidson Giordano Pinto de Carvalho ${ }^{4}$, Leandro Sampaio Oliveira Ribeiro ${ }^{5}$, Jurandir Ferreira da Cruz ${ }^{6}$, Fabiano Ferreira da Silva 3,7}

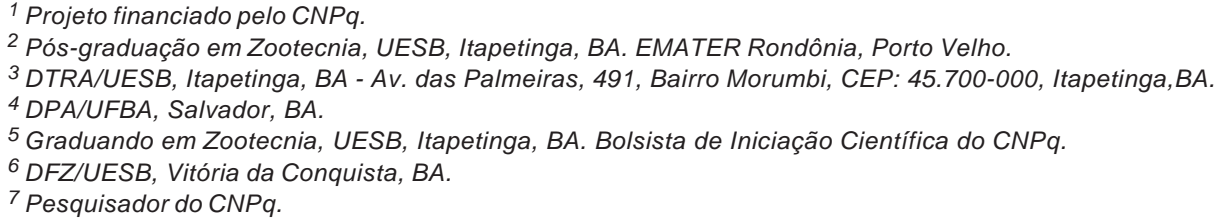

RESUMO - O experimento foi conduzido para avaliar o consumo, a digestibilidade aparente e a produção do leite em cabras alimentadas com silagens de capim-elefante contendo subprodutos industriais. Utilizaram-se oito cabras da raça Saanen, distribuídas em dois quadrados latinos $4 \times 4$, com 4 períodos de 14 dias (10 dias de adaptação e 4 dias para coleta de dados). Os tratamentos foram: silagem de capim-elefante + concentrado; silagem de capim-elefante com 15\% de farelo de mandioca + concentrado; silagem de capim-elefante com 15\% de casca de café + concentrado; silagem de capim-elefante com 15\% farelo de cacau + concentrado. Os maiores consumos de matéria seca (MS), matéria orgânica (MO), carboidratos totais (CT), carboidratos não-fibrosos (CNF) e nutrientes digestíveis totais foram observados entre os animais alimentados com a silagem contendo farelo de mandioca. As silagens com farelo de mandioca ou casca de café promoveram maior consumo de extrato etéreo. Os maiores valores de digestibilidade da MS, MO, EE e CT foram obtidos na dieta contendo silagem de capim-elefante com farelo de mandioca. O valor de digestibilidade dos CNF foi semelhante entre as dietas contendo silagem de capim-elefante com farelo de mandioca, casca de café e farelo de cacau. A digestibilidade de fibra em detergente neutro e de fibra em detergente ácido foi maior para a silagem sem aditivo, com farelo de mandioca ou farelo de cacau. Entre os subprodutos avaliados, o farelo de mandioca é o que promove maiores consumos, digestibilidades dos nutrientes e produção de leite em cabras alimentadas com silagem de capim-elefante.

Palavras-chave: caprinos, conservação, resíduo, silagem

\section{Industrial by-products in elephant grass silage for dairy goats: intake, nutrient digestibility and milk yield}

\footnotetext{
ABSTRACT - The experiment was carried out to evaluate the intake, apparent digestibility and the milk yield of goats fed elephant grass silages containing industrial by-products. Eight Saanen breed goats were used, distributed in two $4 \times 4$ Latin squares, with four 14-day periods (ten days of adaptation and four days for data collection). The treatments were: elephant grass silage + concentrate; elephant grass silage containing 15\% cassava meal + concentrate; elephant grass silage containing $15 \%$ coffee hulls + concentrate; elephant grass silage containing $15 \%$ cocoa meal + concentrate. The greatest intakes of dry matter (DM), organic matter (OM), total carbohydrates (TC), nonfiber carbohydrate (NFC) and digestible total nutrients were observed in the animals fed silage containing cassava meal. The greatest intake of ether extract was verified in the silages with cassava meal or coffee hulls. The greatest digestibility values of the DM, OM, EE and TC were obtained in the diet containing elephant grass silage with cassava meal. The NFC digestibility value was similar among diets containing elephant grass silage with cassava meal, coffee hulls and cocoa meal. The neutral detergent fiber and acid detergent fiber digestibility was greater in the silage without additive, with cassava meal or cocoa meal. Greater intake, digestibility coefficients and milk yield were obtained in goats fed elephant grass silage containing cassava meal.
}

Key Words: by-product, conservation, goats, residue, silage 


\section{Introdução}

A raça de caprinos leiteiros mais difundida no mundo é a Saanen, cujo crescimento é bastante significativo em nosso País, em decorrência de sua maior produção de leite. No Brasil, em criatórios adequadamente manejados e com animais de boa genética, obtêm-se produções médias de 2 a 3 litros de leite por dia e essa produção podendo chegar de 6 a 8 litros por dia em duas ordenhas (Ribeiro, 1998).

A alimentação dos animais representa o maior custo da atividade pecuária (Martins et al., 2000), principalmente quando se usam fontes suplementares de alta qualidade nutricional. Neste sentido, a utilização de alternativas alimentares de menor custo, mas que promovam bons desempenhos nos animais, é necessária para melhorar a relação custo/benefício. Vários subprodutos originados de processamentos nas indústrias, entretanto, apresentam potencial para uso na alimentação animal e podem reduzir os custos da produção (Silva et al., 2002).

O farelo de mandioca, a casca de café e o farelo de cacau são alimentos com potencial para uso na alimentação de ruminantes (Pires et al., 2009) e, se utilizados na ensilagem de gramíneas tropicais com elevada umidade, podem aumentar o teor de matéria seca e melhorar o valor nutritivo da silagem produzida.

A expressão do coeficiente de digestibilidade em percentual indica a quantidade de cada nutriente do alimento que o animal potencialmente pode aproveitar (Van Soest, 1994). O coeficiente de digestibilidade pode sofrer influência da composição e do preparo dos alimentos, da dieta, de fatores dependentes dos animais, bem como do nível nutricional, particularmente a densidade energética da ração (Alves et al., 2003), portanto, é uma variável de grande importância no sistema de avaliação nutricional de dietas.

Este trabalho foi conduzido para avaliar o consumo, a digestibilidade dos nutrientes e a produção de leite de cabras Saanen alimentadas com silagem de capim-elefante contendo farelo de mandioca, casca de café ou farelo de cacau.

\section{Material e Métodos}

O experimento foi realizado no Setor de Caprinocultura do Campus Juvino Oliveira e no Laboratório de Forragicultura e Pastagem da Universidade Estadual do Sudoeste da Bahia, na cidade de Itapetinga, Bahia.

Foram utilizadas oito cabras da raça Saanen, com peso médio de $50 \mathrm{~kg} \pm 5$, aos 40 dias de lactação. As cabras foram distribuídas em dois quadrados latinos $4 \times 4$, conduzidos de forma simultânea, e alimentadas com dietas compostas de silagem de capim-elefante como volumoso, contendo 15\% de farelo de mandioca, casca de café ou farelo de cacau e concentrado. O capim-elefante foi proveniente de capineira já estabelecida, cortado manualmente, rente ao solo, quando apresentava altura média de $1,80 \mathrm{~m}$ aos 80 dias de crescimento, e picado em partículas de aproximadamente $1 \mathrm{~cm}$ em máquina ensiladeira acoplada a um trator.

Foram utilizados como silos tambores de metal com volume de 200 litros (capacidade para $90 \mathrm{~kg}$ da mistura fresca, numa densidade de $450 \mathrm{~kg} / \mathrm{m}^{3}$ ), que foram mantidos fechados por 90 dias. Os subprodutos agroindustriais foram adicionados à forragem recém-picada na proporção de 15\% com base na matéria natural.

O período experimental foi de 56 dias, divididos em 4 períodos de 14 dias (os 10 primeiros de adaptação e os 4 finais de coleta de amostras). As cabras receberam dietas contendo $60 \%$ de volumoso e $40 \%$ de concentrado.

A dieta controle foi composta de 50,31\% de milho; 45,26\% de farelo de soja; e 4,43\% de mistura mineral; a dieta com farelo de mandioca, de 45,26\% de milho; 50,31\% de farelo de soja; e 4,43\% de mistura mineral; a dieta com casca de café, de $52,81 \%$ de milho; $42,76 \%$ de farelo de soja; e $4,43 \%$ de mistura mineral; e a dieta com farelo de cacau, 67,90\% de milho; $27,67 \%$ de farelo de soja; 4,43\% de mistura mineral (Tabela 1). As dietas isoproteicas (16\% de PB) foram formuladas de forma atender às exigências de mantença (baixa atividade) e lactação para produção de 2,5 kg de leite/dia, segundo o NRC (1981).

Tabela 1 - Composição nutricional dos ingredientes utilizados nas dietas experimentais

\begin{tabular}{|c|c|c|c|c|c|c|}
\hline Item & Milho & Farelo de soja & Farelo de mandioca & Casca de café & Farelo de cacau & Capim-elefante \\
\hline Matéria seca & 85,3 & 89,2 & 87,8 & 89,9 & 89,6 & 24,5 \\
\hline Matéria orgânica (\%MS) & 98,5 & 93,5 & 98,5 & 96,0 & 90,6 & 91,7 \\
\hline Matéria mineral (\%MS) & 1,5 & 6,5 & 1,5 & 4,0 & 9,4 & 8,3 \\
\hline Proteína bruta (\%MS) & 10,1 & 49,5 & 2,0 & 6,5 & 16,9 & 6,4 \\
\hline NIDN/NT (\% NT) & 3,5 & 4,4 & 6,9 & 50,1 & 42,0 & 10,9 \\
\hline Extrato etéreo (\%MS) & 3,5 & 2,9 & 0,5 & 1,0 & 5,3 & 4,5 \\
\hline Fibra em detergente neutro (\%MS) & 13,4 & 15,2 & 20,2 & 73,5 & 51,4 & 75,0 \\
\hline Fibra em detergente ácido (\%MS) & 5,0 & 9,0 & 5,8 & 54,9 & 45,7 & 54,3 \\
\hline Lignina (\%MS) & 0,4 & 0,1 & 1,0 & 16,1 & 15,6 & 5,4 \\
\hline Carboidratos totais (\%MS) & 84,9 & 41,1 & 96 & 88,5 & 68,4 & 80,8 \\
\hline Carboidratos não-fibrosos (\%MS) & 71,5 & 25,9 & 75,8 & 15,0 & 17,0 & 5,8 \\
\hline
\end{tabular}

NIDN = nitrogênio insolúvel em detergente neutro; NT = nitrogênio total. 
A coleta de fezes para avaliação da digestibilidade foi realizada durante os quatro dias finais de cada período experimental, com auxílio de uma tela de náilon fixa abaixo do piso ripado de madeira em cada baia.

Diariamente foram pesados o volumoso, o concentrado, as sobras e o leite produzido. As amostras das dietas oferecidas, das sobras e das fezes foram coletadas nos quatro últimos dias do final de cada período, formando uma mistura composta por animal e por período, mantidas e acondicionadas em freezer a $-10{ }^{\circ} \mathrm{C}$. Posteriormente foram descongeladas, homogeneizadas e colocadas em estufa a $60^{\circ} \mathrm{C}$ com ventilação forçada por 72 horas para présecagem. Em seguida, foram trituradas em moinho tipo Wiley, utilizando-se peneira com crivos de $1 \mathrm{~mm}$ de diâmetro, e armazenadas para posteriores análises químicas.

As análises de matéria seca (MS), matéria orgânica (MO), nitrogênio total (NT), extrato etéreo (EE), fibra em detergente neutro (FDN), fibra em detergente ácido (FDA) e os teores de nitrogênio insolúvel em detergente neutro (NIDN), expressos em porcentagem do NT, foram realizadas segundo procedimentos descritos por Silva \& Queiroz (2002). O teor de carboidratos totais (CT) foi calculado segundo equações propostas por Sniffen et al. (1992), em que CT = 100 - (\%PB + \%EE + \%Cinzas), e os teores de carboidratos não-fibrosos (CNF), pela equação: $\mathrm{CNF}=\mathrm{CT}-\mathrm{FDN}_{\mathrm{cp}}$ (Tabela 2).

O teor de nutrientes digestíveis totais (NDT) observado foi obtido a partir da equação somativa: $\mathrm{NDT}=\mathrm{PBD}+2,25 \times \mathrm{EED}+\mathrm{FDNpD}+\mathrm{CNFD}$, em que PBD, EED, FDNpD e CNFD significam, respectivamente, proteína bruta digestível, extrato etéreo digestível, fibra em detergente neutro (isenta de proteína) digestível e carboidratos não-fibrosos digestíveis, segundo Weiss (1999).

$\mathrm{O}$ teor de gordura do leite foi determinado pelo método de centrifugação, usando butirômetro de GergerVan Gulik, e a produção diária de leite corrigida para 3,5\% de gordura (PLCG) foi calculada como: $P L C G=(0,432+$
$0,11625 \times$ \% de gordura do leite) $\times$ produção de leite em $\mathrm{kg} / \mathrm{dia}$ (Sklan et al., 1992).

Os dados foram submetidos à análise de variância e ao teste Tukey, adotando-se o nível de significância de $5 \%$ de probabilidade, utilizando-se o programa Sistema de Análises Estatísticos e Genéticos - SAEG (Ribeiro Jr., 2001).

\section{Resultados e Discussão}

Os consumos de MS e MO nas silagens de capimelefante contendo farelo de mandioca foram superiores $(\mathrm{P}<0,05)$ aos das dietas com silagem sem aditivo e contendo casca de café ou farelo cacau, independentemente da forma como foram expressos, $\mathrm{kg} / \mathrm{dia}$, \% peso corporal (\%PC) ou $\mathrm{g} / \mathrm{kg}^{0,75}$, essas duas últimas semelhantes entre si (Tabela 3).

O maior consumo de MS na silagem de capim-elefante com farelo de mandioca pode estar relacionado ao fato de o farelo de mandioca apresentar baixo teor de fibra em detergente neutro e elevado teor de carboidratos nãofibrosos (Tabela 1), o que contribuiu para a melhoria dos parâmetros digestivos.

Vários estudos têm comprovado correlação negativa entre o consumo de MS e o teor de FDN da dieta e essa correlação tem sido associada à menor taxa de passagem da FDN em relação aos outros constituintes dietéticos, que, por sua vez, promove o enchimento do rúmen-retículo elevando a permanência da digesta nos compartimentos (Menezes et al., 2004; Mertens, 1992).

Os maiores consumos de PB ( $\mathrm{kg} / \mathrm{dia}$ ) foram verificados nas silagens com farelo de mandioca e com farelo de cacau $(\mathrm{P}<0,05)$, as quais apresentaram valores de 0,306 e $0,271 \mathrm{~kg} /$ dia, respectivamente. A silagem de capim-elefante contendo farelo de cacau, entretanto, não diferiu $(\mathrm{P}>0,05)$ da silagem sem aditivo e daquela com casca de café, cujos valores foram 0,240 e $0,245 \mathrm{~kg} /$ dia, respectivamente. O consumo de

Tabela 2 - Composição nutricional das dietas experimentais (\% MS)

\begin{tabular}{|c|c|c|c|c|}
\hline \multirow[t]{2}{*}{ Item $(\%)^{1}$} & \multicolumn{4}{|c|}{ Silagem de capim-elefante } \\
\hline & Sem aditivo & Farelo de mandioca (\%) & Casca de café (\%) & Farelo de cacau (\%) \\
\hline Matéria seca & 50,0 & 53,7 & 54,9 & 55,2 \\
\hline Proteína bruta & 15,7 & 15,4 & 15,5 & 16,9 \\
\hline $\mathrm{NIDN} / \mathrm{NT}^{2}$ & 7,9 & 6,5 & 8,9 & 12,4 \\
\hline Extrato etéreo & 5,0 & 5,2 & 5,3 & 5,2 \\
\hline Carboidratos totais & 71,7 & 72,9 & 72,2 & 69,6 \\
\hline Carboidratos não-fibrosos & 24,5 & 37,0 & 24,1 & 25,9 \\
\hline Cinzas & 7,6 & 6,5 & 6,8 & 7,4 \\
\hline
\end{tabular}

${ }^{1}$ Dados obtidos por análises químicas; ${ }^{2}$ NIDN = nitrogênio insolúvel em detergente neutro, em porcentagem do nitrogênio total. 
proteína bruta calculado em relação ao peso corporal e metabólico não diferiu significativamente $(\mathrm{P}>0,05)$ entre as dietas testadas.

Diferenças no consumo de PB são esperadas, em decorrência das variações no consumo de MS. Assim, o maior consumo de PB na silagem com farelo de mandioca pode ser explicado pela maior ingestão de MS, uma vez que as dietas foram isoproteicas (15\% de PB aproximadamente). Para a silagem com farelo de cacau, no entanto, a equiparação no consumo de PB com a silagem contendo farelo de mandioca ocorreu provavelmente pela maior seleção do concentrado em detrimento à silagem com farelo de cacau, na dieta total, uma vez que os animais não demonstraram boa aceitabilidade ao volumoso e apresentaram menor consumo de MS. Os caprinos têm maior capacidade seletiva por alimentos que outras espécies de ruminantes (Silva, 2003), o que propicia a ingestão de uma dieta mais nutritiva. Os valores de composição química do farelo de cacau e os resultados obtidos para o consumo indicam menor qualidade nutritiva desse aditivo em relação ao farelo de mandioca, que proporcionou maior consumo.

O consumo de EE, independentemente da forma de expressão, foi maior nas silagens com farelo de mandioca e casca de café. O consumo de EE na silagem com a casca de café, entretanto, foi semelhante ao das silagens sem aditivo e com farelo de cacau. O maior consumo de EE observado para a silagem de capim-elefante com farelo de mandioca também pode ser explicado pelo maior consumo de MS (Tabela 3).
Mouro et al. (2002) estudaram a substituição do milho pela farinha de varredura de mandioca ( 0 , 33, 67 e 100\% no concentrado) em dietas para cabras em lactação e observaram decréscimo de 6,61\% no consumo do EE ( $\mathrm{kg} / \mathrm{dia}$ ) para cada unidade percentual de milho substituída, comprovando efeito de diluição, uma vez que o milho apresenta maior teor de EE em comparação à farinha de varredura de mandioca.

A utilização de farelo de mandioca, casca de café e farelo de cacau na ensilagem de capim-elefante não teve efeito $(\mathrm{P}>0,05)$ nos consumos de FDN e FDA (Tabela 4 ). Apesar do maior consumo de MS na silagem com farelo de mandioca, o menor teor de FDN na dieta contendo este subproduto pode ter contribuído para a semelhança entre os consumos de FDN entre as dietas.

Os maiores consumos de carboidratos totais foram observados nas silagens com farelo de mandioca, enquanto aquelas sem aditivo, com casca de café e com farelo de cacau não diferiram $(\mathrm{P}>0,05)$ entresi. Omesmo ocorreu com o consumo de carboidratos não-fibrosos, que foi maior para a silagem com farelo de mandioca e menor para as demais (Tabela 4).

O maior consumo de carboidratos totais e carboidratos não-fibrosos (kg/dia) observado para a dieta com farelo de mandioca pode estar relacionado aos altos teores desses componentes no farelo de mandioca (Tabela 1) e ao elevado consumo de MS (Tabela 4). É comum verificar na literatura (Menezes et al., 2004; Mouro et al., 2002) redução no consumo de matéria seca e, ou ausência de efeito no consumo de nutrientes como carboidratos totais e carboidratos nãofibrosos em dietas com subprodutos de mandioca.

Tabela 3 - Consumo de nutrientes em cabras Saanen alimentadas com silagens de capim-elefante contendo subprodutos agroindustriais

\begin{tabular}{|c|c|c|c|c|c|c|}
\hline \multirow[t]{2}{*}{ Consumo } & \multicolumn{4}{|c|}{ Silagem de capim-elefante } & \multirow[t]{2}{*}{ Média } & \multirow[t]{2}{*}{$\mathrm{CV}(\%$} \\
\hline & Sem aditivo & $\begin{array}{l}\text { Farelo de mandioca } \\
\qquad(15 \% \mathrm{MN})\end{array}$ & $\begin{array}{c}\text { Casca de café } \\
(15 \% \mathrm{MN})\end{array}$ & $\begin{array}{l}\text { Farelo de cacau } \\
(15 \% \mathrm{MN})\end{array}$ & & \\
\hline \multicolumn{7}{|c|}{ Matéria seca } \\
\hline kg/dia & $1,439 b$ & $1,914 a$ & $1,504 b$ & $1,425 b$ & 1,570 & 15,3 \\
\hline$\% \mathrm{PC}$ & $3,73 b$ & $4,64 a$ & $3,68 b$ & $3,61 b$ & 3,91 & 15,0 \\
\hline $\mathrm{g} / \mathrm{kg}^{0,75}$ & $92,7 b$ & $117,2 \mathrm{a}$ & $92,9 b$ & $90,3 b$ & 98,3 & 14,8 \\
\hline \multicolumn{7}{|c|}{ Matéria orgânica } \\
\hline kg/dia & $1,326 b$ & $1,789 a$ & $1,400 b$ & $1,319 b$ & 1,459 & 15,5 \\
\hline$\% \mathrm{PC}$ & $3,44 b$ & 4,33a & $3,43 b$ & $3,34 b$ & 3,64 & 15,1 \\
\hline $\mathrm{g} / \mathrm{kg}^{0,75}$ & $85,4 b$ & $109,5 \mathrm{a}$ & $86,5 b$ & $83,6 b$ & 91,3 & 14,9 \\
\hline \multicolumn{7}{|c|}{ Proteína bruta } \\
\hline kg/dia & $0,240 b$ & $0,306 a$ & $0,245 b$ & $0,271 \mathrm{ab}$ & 0,265 & 15,8 \\
\hline$\% \mathrm{PC}$ & $0,624 a$ & $0,742 \mathrm{a}$ & $0,600 \mathrm{a}$ & $0,686 a$ & 0,663 & 15,6 \\
\hline $\mathrm{g} / \mathrm{kg}^{0,75}$ & $15,5 \mathrm{a}$ & $18,7 \mathrm{a}$ & $15,1 \mathrm{a}$ & $17,2 \mathrm{a}$ & 16,6 & 15,4 \\
\hline \multicolumn{7}{|c|}{ Extrato etéreo } \\
\hline kg/dia & $0,070 \mathrm{~b}$ & $0,098 \mathrm{a}$ & 0,079ab & $0,072 b$ & 0,080 & 18,3 \\
\hline$\%$ PC & $0,18 b$ & $0,24 a$ & $0,19 \mathrm{ab}$ & $0,18 \mathrm{~b}$ & 0,20 & 17,5 \\
\hline $\mathrm{g} / \mathrm{kg}^{0,75}$ & $4,5 b$ & $7,0 \mathrm{a}$ & $4,9 \mathrm{ab}$ & $4,5 b$ & 5,2 & 17,5 \\
\hline
\end{tabular}

\% PC = em porcentagem do peso corporal; g/ $\mathrm{kg}^{0,75}=$ em relação ao peso metabólico; MN - matéria natural.

Médias seguidas de mesma letra na linha não diferem entre si pelo teste Tukey a 5\% de probabilidade. 
Tabela 4 - Consumo de nutrientes em cabras Saanen alimentadas com silagens de capim-elefante contendo subprodutos agroindustriais

\begin{tabular}{|c|c|c|c|c|c|c|}
\hline \multirow[t]{2}{*}{ Consumo } & \multicolumn{4}{|c|}{ Silagem de capim-elefante } & \multirow[t]{2}{*}{ Média } & \multirow[t]{2}{*}{ CV $(\%)$} \\
\hline & Sem aditivo & $\begin{array}{l}\text { Farelo de mandioca } \\
\qquad(15 \% \mathrm{MN})\end{array}$ & $\begin{array}{c}\text { Casca de café } \\
(15 \% \mathrm{MN})\end{array}$ & $\begin{array}{l}\text { Farelo de cacau } \\
\quad(15 \% \mathrm{MN})\end{array}$ & & \\
\hline \multicolumn{7}{|c|}{ Fibra em detergente neutro } \\
\hline kg/dia & $0,754 a$ & $0,791 \mathrm{a}$ & $0,810 \mathrm{a}$ & $0,718 \mathrm{a}$ & 0,768 & 15,1 \\
\hline$\% \mathrm{PC}$ & $1,94 a$ & $1,92 \mathrm{a}$ & $1,98 a$ & $1,82 \mathrm{a}$ & 1,92 & 15,8 \\
\hline $\mathrm{g} / \mathrm{kg}^{0,75}$ & $48,4 a$ & $45,8 \mathrm{a}$ & $49,9 \mathrm{a}$ & $45,5 \mathrm{a}$ & 48,1 & 15,4 \\
\hline \multicolumn{7}{|c|}{ Fibra em detergente ácido } \\
\hline $\mathrm{kg} /$ dia & $0,457 \mathrm{a}$ & $0,472 \mathrm{a}$ & $0,534 \mathrm{a}$ & $0,523 a$ & 0,497 & 13,7 \\
\hline$\% \mathrm{PC}$ & $1,17 \mathrm{a}$ & $1,14 \mathrm{a}$ & $1,30 \mathrm{a}$ & $1,32 \mathrm{a}$ & 1,24 & 13,8 \\
\hline $\mathrm{g} / \mathrm{kg}^{0,75}$ & $29,2 \mathrm{a}$ & $28,9 a$ & $33,0 \mathrm{a}$ & $33,1 \mathrm{a}$ & 31,0 & 13,5 \\
\hline \multicolumn{7}{|c|}{ Carboidratos totais } \\
\hline kg/dia & $1,017 \mathrm{~b}$ & $1,384 a$ & $1,076 b$ & $0,975 b$ & 1,113 & 15,3 \\
\hline$\% \mathrm{PC}$ & $2,63 \mathrm{~b}$ & $3,35 a$ & $2,63 b$ & $2,47 b$ & 2,77 & 14,9 \\
\hline $\mathrm{g} / \mathrm{kg}^{0,75}$ & $65,4 \mathrm{~b}$ & $84,7 \mathrm{a}$ & $66,4 \mathrm{~b}$ & $61,9 b$ & 69,6 & 14,8 \\
\hline \multicolumn{7}{|c|}{ Carboidratos não fibrosos } \\
\hline $\mathrm{kg} / \mathrm{dia}$ & $0,390 \mathrm{~b}$ & $0,736 \mathrm{a}$ & $0,391 b$ & $0,388 b$ & 0,476 & 18,3 \\
\hline$\% \mathrm{PC}$ & $1,02 b$ & $1,78 \mathrm{a}$ & $0,96 b$ & $0,99 b$ & 1,18 & 16,1 \\
\hline $\mathrm{g} / \mathrm{kg}^{0,75}$ & $25,2 b$ & $44,9 a$ & $24,2 b$ & $24,6 b$ & 29,8 & 16,4 \\
\hline \multicolumn{7}{|c|}{ Nutrientes digestíveis totais } \\
\hline kg/dia & $0,962 b$ & $1,395 \mathrm{a}$ & $0,958 b$ & $0,936 b$ & 1,063 & 18,9 \\
\hline$\% \mathrm{PC}$ & $2,48 b$ & $3,41 \mathrm{a}$ & $2,34 b$ & $2,37 b$ & 2,65 & 18,9 \\
\hline $\mathrm{g} / \mathrm{kg}^{0,75}$ & $61,8 b$ & $85,9 a$ & $59,1 b$ & $59,2 b$ & 66,5 & 18,7 \\
\hline
\end{tabular}

$\% \mathrm{PC}=$ em porcentagem do peso corporal; $\mathrm{g} / \mathrm{kg}^{0,75}=$ em relação ao peso metabólico; $\mathrm{MN}$ - matéria natural.

Médias seguidas por uma mesma letra na linha não diferem entre si pelo teste Tukey a 5\% de probabilidade.

A silagem com farelo de mandioca proporcionou maior consumo de NDT $(1,395 \mathrm{~kg} /$ dia $)$ em relação às demais silagens, que não diferiram $(\mathrm{P}<0,05)$ entre si. Esse resultado pode ser explicado pelo aumento nos consumos de EE e CNF, frações de alta digestibilidade e elevado valor energético, uma vez que não foi verificado efeito no consumo de FDN.

A dieta com silagem de capim-elefante contendo farelo de mandioca foi a que apresentou maior digestibilidade aparente, tanto para a MS como para a MO, cujos valores foram, respectivamente, de 68,7 e 70,3\% (Tabela 5). As demais silagens, sem aditivo, casca de café e farelo de cacau, não diferiram entre si $(\mathrm{P}>0,05)$.
Os maiores valores obtidos para as digestibilidades de MS e MO na silagem com farelo de mandioca estão relacionados aos maiores teores de nutrientes digestíveis dessa dieta, o que promoveu maior aproveitamento desses nutrientes pelas bactérias ruminais. O elevado teor de amido e de carboidratos de rápida fermentação ruminal no farelo de mandioca também explica os maiores coeficientes de digestibilidade da MS e MO. Os menores coeficientes obtidos para as silagens sem aditivos, com farelo de cacau e casca de café podem estar relacionados, em sua maior parte, à composição das dietas, visto que esses subprodutos apresentam maiores teores de lignina, FDN e NIDN (Tabela 1), que interferem diretamente na digestibilidade.

Tabela 5 - Digestibilidade dos nutrientes da dieta em cabras Saanen alimentadas com silagens de capim-elefante contendo subprodutos agroindustriais

\begin{tabular}{|c|c|c|c|c|c|c|}
\hline \multirow[t]{2}{*}{ Digestibilidade } & \multicolumn{4}{|c|}{ Silagem de capim-elefante } & \multirow[t]{2}{*}{ Média } & \multirow[t]{2}{*}{ CV (\%) } \\
\hline & Sem aditivo & $\begin{array}{l}\text { Farelo de mandioca } \\
\qquad(15 \% \mathrm{MN})\end{array}$ & $\begin{array}{c}\text { Casca de café } \\
(15 \% \mathrm{MN})\end{array}$ & $\begin{array}{l}\text { Farelo de cacau } \\
\qquad(15 \% \mathrm{MN})\end{array}$ & & \\
\hline Matéria seca & $62,3 \mathrm{~b}$ & $68,7 \mathrm{a}$ & $58,7 \mathrm{~b}$ & $60,0 \mathrm{~b}$ & 62,4 & 5,6 \\
\hline Matéria orgânica & $63,7 \mathrm{~b}$ & $70,3 a$ & $59,9 b$ & $61,2 b$ & 63,8 & 5,4 \\
\hline Proteína bruta & $71,0 \mathrm{a}$ & $70,8 a$ & $68,4 \mathrm{a}$ & $67,7 \mathrm{a}$ & 69,5 & 6,1 \\
\hline Extrato etéreo & $58,7 \mathrm{ab}$ & $66,6 a$ & $57,9 b$ & $53,7 \mathrm{~b}$ & 59,2 & 9,4 \\
\hline Carboidratos totais & $62,4 b$ & $70,4 a$ & $58,1 b$ & $60,0 \mathrm{~b}$ & 62,7 & 6,0 \\
\hline Carboidratos não-fibrosos & $79,7 b$ & $85,2 \mathrm{a}$ & $84,1 \mathrm{ab}$ & $82,7 \mathrm{ab}$ & 82,9 & 4,3 \\
\hline Fibra em detergente neutro & $50,2 \mathrm{ab}$ & $52,1 \mathrm{a}$ & $42,9 b$ & $45,1 \mathrm{ab}$ & 47,6 & 13,1 \\
\hline Fibra em detergente ácido & $46,6 a b$ & 48,8 a & $33,0 \mathrm{~b}$ & $49,6 a$ & 44,5 & 23,8 \\
\hline
\end{tabular}

Médias seguidas por uma mesma letra na linha não diferem entre si pelo teste Tukey a 5\% de probabilidade.

MN - matéria natural. 
Semelhante aos dados obtidos neste trabalho, Silva et al. (2005) reportaram valores de digestibilidade de MS e MO, respectivamente, de 66,07 e 68,37\% para uma dieta contendo $15 \%$ de farelo de cacau em cabras em lactação. A digestibilidade da $\mathrm{PB}$ não diferiu $(\mathrm{P}>0,05)$ entre as silagens estudadas e seu valor médio foi de $69,5 \%$, comprovando que a digestibilidade aparente da PB não foi influenciada pela inclusão de $15 \%$ dos subprodutos na ensilagem do capim-elefante.

Esperava-se menor digestibilidade da PB da dieta contendo silagem de capim-elefante com farelo de cacau, tendo em vista os elevados teores de NIDN neste subproduto (Tabela 1), contudo, os animais alimentados com essa silagem selecionaram a dieta, rejeitando-a, fato que pode ter contribuído para semelhança da digestibilidade da PB com as demais silagens.

Silva et al. (1999), em pesquisa com cabras leiteiras alimentadas com dietas contendo diferentes relações volumoso:concentrado, observaram a habilidade seletiva das cabras em revirar as dietas, fazendo com que o concentrado se acumulasse no fundo do cocho para facilitar sua apreensão. Neste trabalho verificou-se a preferência dos animais pelo volumoso, rejeitando o farelo de cacau que ficava no fundo do cocho. É possível que o cheiro acentuado de chocolate no farelo de cacau tenha favorecido o baixo consumo, uma vez que a silagem apresentou boa aparência e pH dentro da faixa recomendada para silagens bem fermentadas (Carvalho et al., 2007; Carvalho et al., 2008). Do mesmo modo, Silva et al. (2005) realizaram estudos com cabras leiteiras alimentadas com dietas contendo 15 e 30\% de farelo de cacau ou torta de dendê no concentrado e não verificaram diferenças nos coeficientes de digestibilidade da $\mathrm{PB}$, de modo que a digestibilidade da PB da dieta contendo $15 \%$ de farelo de cacau no concentrado foi de $58,60 \%$. Esses autores também observaram que os animais selecionaram o volumoso, rejeitando o concentrado com 30\% de farelo de cacau. Com os resultados observados neste trabalho e em outros verificados na literatura (Oliveira, 2005; Silva et al., 2005), fica evidenciado, portanto, que o farelo de cacau não tem boa aceitação por caprinos.

A digestibilidade do extrato etéreo foi maior $(\mathrm{P}<0,05)$ para as silagens sem aditivo e com farelo de mandioca (Tabela 5), com valores de 58,7 e 66,6\%, respectivamente. Já as silagens com casca de café e farelo de cacau não apresentaram diferenças $(\mathrm{P}>0,05)$, com valores de 57,9 e 53,7\%, respectivamente, porém, a silagem sem aditivo não diferiu $(\mathrm{P}>0,05)$ daquelas com casca de café e farelo de cacau.

A maior digestibilidade do extrato etéreo observada para a silagem contendo farelo de mandioca (Tabela 5), a qual apresenta baixo teor de EE (Tabela 1), pode ser explicada pelo maior consumo de MS, tendo em vista a baixa rejeição dessa dieta, sobretudo das silagens contendo casca de café e farelo de cacau, as quais tiveram baixa digestibilidade.

São encontrados na literatura vários trabalhos relatando decréscimo da digestibilidade do EE (Silva et al., 2005; Sousa, 2005) quando utilizado farelo de cacau na composição de dietas para caprinos. Em todos esses trabalhos foram apontados menores consumos de MS quando fornecido farelo de cacau. Os resultados obtidos neste estudo estão de acordo com os relatados por Silva et al. (2005) e Sousa (2005).

A silagem contendo farelo de mandioca apresentou maior $(\mathrm{P}>0,05)$ digestibilidade dos carboidratos totais, com valor médio de 70,4\%. As dietas sem aditivo, com casca de café ou farelo de cacau não diferiram $(\mathrm{P}>0,05)$ entre si, com valores médios, respectivamente, de 62,4; 58,1 e 60,0\% (Tabela 5). Esses achados podem ser explicados pelo fato de o farelo de mandioca apresentar maior teor de carboidratos totais em sua composição nutricional (Tabela 1), uma vez que, dessa fração 75,8\% são carboidratos não-fibrosos, material rapidamente fermentável no rúmen.

Abrahão et al. (2006), em pesquisa com o subproduto úmido de mandioca em substituição ao milho $(0 ; 25 ; 50 ; 75$; $100 \%$ no concentrado), observaram que não houve diferença entre os níveis de substituição e que o valor médio de digestibilidade dos carboidratos totais foi de $66,0 \%$. De acordo com os autores, isso ocorreu provavelmente porque o milho e o resíduo úmido de mandioca possuem teores semelhantes de carboidratos totais. O valor encontrado neste trabalho foi maior, uma vez que o subproduto foi incluído no volumoso no momento da ensilagem (Tabela 5).

$\mathrm{O}$ farelo de mandioca se destaca entre os demais aditivos pelo maior teor de CNF em sua composição (Tabela 1 ), gerando dietas com maiores $(\mathrm{P}<0,05)$ valores de CNF. Contudo, a digestibilidade desses carboidratos não diferiu $(\mathrm{P}>0,05)$ entre as silagens de capim-elefante com farelo de mandioca, casca de café ou farelo de cacau, cujos valores foram, respectivamente, de 85,2; 84,1; 82,7\%. A silagem sem aditivo (79,7\%), no entanto, não diferiu $(\mathrm{P}>0,05)$ daquelas com casca de café ou farelo de cacau.

Mouro et al. (2002) avaliaram a substituição do milho pela farinha de varredura de mandioca (0, 33, 67 e $100 \%$ no concentrado) em dietas para cabras e verificaram que não houve efeito $(\mathrm{P}>0,05)$ na digestibilidade dos carboidratos não-fibrosos, cujo valor médio foi 93,79\%.

Neste estudo, a digestibilidade da FDN foi semelhante $(\mathrm{P}>0,05)$ entre as silagens sem aditivo, com farelo de mandioca e com farelo de cacau e apresentou valores médios de 50,2; 
52,1 e 45,1\%, respectivamente. A dieta com casca de café $(42,9 \%)$ não diferiu $(\mathrm{P}>0,05)$ daquelas sem aditivo e com farelo de cacau (Tabela 5). Comportamento semelhante ocorreu com a digestibilidade da FDA, cujos resultados observados foram similares $(\mathrm{P}>0,05)$ para as silagens sem aditivo e com farelo de mandioca ou farelo de cacau, com valores médios de 46,6; 48,8 e 49,6\%, respectivamente. A digestibilidade da FDA da dieta contendo silagem de capimelefante com casca de café $(33,0 \%)$ foi semelhante ( $\mathrm{P}>0,05)$ apenas à da silagem sem aditivo.

A menor digestibilidade da FDN e FDA da silagem de capim-elefante com casca de café pode ser atribuída à influência do elevado teor de lignina na casca de café (Tabela 1), componente diretamente relacionado à digestibilidade da fibra, que limita a digestão dos polissacarídeos da parede celular pelos microrganismos. Souza et al. (2001) verificaram baixos valores de digestibilidade in vitro da fração fibrosa da casca de café, cujo valor médio foi de $26,65 \%$.

As digestibilidades da FDN e FDA na dieta contendo silagem de capim-elefante com farelo de mandioca estão de acordo com os estudos de Jung \& Allen (1995), portanto, é possível que dietas com menor concentração de FDN contribuam para aumentar o consumo de matéria seca e ao mesmo tempo elevar a densidade energética da ração para ruminantes. Essa condição favorece os microrganismos ruminais, aumentando a eficiência do ataque à fibra, e melhorando a digestibilidade.

A maior produção de leite foi obtida com a silagem com farelo de mandioca, enquanto as dietas com silagem sem aditivo, casca de café e farelo de cacau não diferiram entre si $(\mathrm{P}>0,05)$. O mesmo ocorreu com a produção de leite corrigida, cujos valores foram de 0,984; 1,241; 0,897 e 0,938 kg/dia, respectivamente. Todavia, a PL/kg de MS consumida não diferiu $(\mathrm{P}>0,05)$ entre as dietas estudadas e apresentou relação média de 0,834 de leite/kg de MS.

A maior produção de leite obtida (1,605 kg/dia) com o uso da silagem de capim-elefante com farelo de mandioca pode ser atribuída ao maior consumo de MS (1,914 kg/dia) e NDT (1,395 kg/dia) desta dieta (Tabelas 3 e 4). Além do maior consumo, o farelo de mandioca apresentou em sua composição nutrientes mais digestíveis em comparação aos demais subprodutos estudados. A maior produção de leite corrigida (Tabela 6) quando fornecida a silagem com farelo de mandioca seguiu a mesma tendência observada para a produção de leite.

A ausência de efeito $(\mathrm{P}>0,05)$ para a $\mathrm{PL} / \mathrm{kg}$ de MS consumida pode ser atribuída às dietas analisadas, o que está associado à capacidade de transformar a MS ingerida em kg de leite. Embora as eficiências não tenham apresentado diferença entre as silagens, o consumo de nutrientes e a produção de leite foram influenciados pelo uso dos aditivos na ensilagem. A semelhança nos resultados de eficiência (PL/kg de MS consumida) obtidos neste estudo indica que as silagens contendo os aditivos casca de café ou farelo de cacau poderiam ter promovido produção de leite similar à silagem com farelo de mandioca, caso os animais tivessem apresentado capacidade ingestiva (consumo) semelhante.

Avaliando a substituição do milho pela farinha de mandioca de varredura (0, 33, 67 e $100 \%$ no concentrado) em dietas para cabras em lactação, Mouro et al. (2002) relataram que não houve interferência dos níveis de substituição sobre a produção de leite $(2,1 \mathrm{~kg} /$ dia $)$, uma vez que esses resultados estão associados a uma ingestão média de $1,8 \mathrm{~kg} /$ dia de MS.

Tabela 6 - Produção de leite em cabras Saanen alimentadas com silagens de capim-elefante contendo subprodutos agroindustriais

\begin{tabular}{|c|c|c|c|c|c|c|}
\hline Item & \multicolumn{3}{|c|}{ Silagem de capim-elefante } & $\begin{array}{c}\text { Farelo de cacau } \\
(15 \% \mathrm{MN})\end{array}$ & Média & CV $(\%)$ \\
\hline Produção de leite corrigida (kg/dia) & 0,984b & $1,241 \mathrm{a}$ & 0,897b & $0,938 b$ & 1,015 & 10,7 \\
\hline Produção de leite por kg MS & $0,894 \mathrm{a}$ & $0,865 a$ & $0,765 a$ & $0,812 \mathrm{a}$ & 0,834 & 14,4 \\
\hline
\end{tabular}

Médias seguidas por uma mesma letra na linha não diferem entre si pelo teste Tukey a 5\% de probabilidade. MN - matéria natural.

\section{Conclusões}

A silagem de capim-elefante contendo 15\% de farelo de mandioca em dietas para cabras leiteiras aumenta o consumo de matéria seca e a produção de leite. A inclusão de $15 \%$ de farelo de mandioca na ensilagem de capim- elefante em dietas para cabras leiteiras melhora a digestibilidade dos nutrientes em comparação a outros subprodutos agroindustriais, como a casca de café ou o farelo de cacau. Não se justifica produzir silagens de capim-elefante com casca de café ou farelo de cacau para alimentar cabras leiteiras. 


\section{Referências}

ABRAHAO, J.J.S.; PRADO, I.N.; PEROTTO, D. et al. Digestibilidade de dietas contendo resíduo úmido de mandioca em substituição ao milho para tourinhos em terminação. Revista Brasileira de Zootecnia, v.35, n.4, p.1447-1453, 2006.

ALVES, K.S.; CARVALHO, F.F.R.; VÉRAS, A.S.C. et al. Níveis de energia em dietas para ovinos Santa Inês: digestibilidade aparente. Revista Brasileira de Zootecnia, v.32, n.6, p.1962-1968, 2003 (supl. 2).

CARVALHO, G.G.P.; GARCIA, R.; PIRES, A.J.V. et al. Valor nutritivo e características de silagem de capim-elefante com adição de casca de café. Revista Brasileira de Zootecnia, v.36, n.6, p.1875-1881, 2007.

CARVALHO, G.G.P.; GARCIA, R.; PIRES, A.J.V. et al. Características fermentativas de silagens de capim-elefante emurchecido ou com adição de farelo de cacau. Arquivo Brasileiro de Medicina Veterinária e Zootecnia, v.60, n.1, p.234-1242, 2008.

JUNG, H.G.; ALLEN, S. Characteristics of plant cell walls affecting intake and digestibility of forages by ruminants. Journal of Dairy Science, v.73, n.9, p.2774-2790, 1995.

MARTINS, A.S.; PRADO, I.N.; ZEOULA, L.M. et al. Digestibilidade aparente de dietas contendo milho ou casca de mandioca como fonte energética e farelo de algodão ou levedura como fonte protéica em novilhas. Revista Brasileira de Zootecnia, v.29, n.1, p.269-277, 2000.

MENEZES, M.P.C.; RIBEIRO, M.N.; COSTA, R.G. et al. Substituição do milho pela casca de mandioca (Manihot esculenta Crants) em rações completas para caprinos: consumo, digestibilidade de nutrientes e ganho de peso. Revista Brasileira de Zootecnia, v.33, n.3, p.729-737, 2004.

MERTENS, D.R. Analysis of fiber in feeds and its uses in feed evaluation and ration formulation. In: SIMPÓSIO INTERNACIONAL DE RUMINANTES, REUNIÃO ANUAL DA SOCIEDADE BRASILEIRA DE ZOOTECNIA, 29., 1992, Lavras. Anais... Lavras: Sociedade Brasileira de Zootecnia, 1992. p.1-32.

MOURO, G.F.; BRANCO, A.F.; MACEDO, F.A.F. et al. Substituição do milho pela farinha de mandioca de varredura em dietas de cabras em lactação: produção e composição do leite e digestibilidade dos nutrientes. Revista Brasileira de Zootecnia, v.31, n.1, p.475-483, 2002 (supl. 1).

NATIONAL RESEARCH COUNCIL - NRC. Nutrient requirements of goats. Washington, D.C.: National Academy Press, 1981. $91 \mathrm{p}$.

OLIVEIRA, A.R.A. Níveis de utilização de farelo de cacau (Theobroma cacao L.) na alimentação de caprinos em crescimento. 2005. 47f. Dissertação (Mestrado em Zootecnia) Universidade Estadual do Sudoeste da Bahia, Itapetinga.
PIRES, A.J.V,; CARVALHO, G.G.P.; GARCIA, R. et al. Capimelefante ensilado com casca de café, farelo de cacau ou farelo de mandioca. Revista Brasileira de Zootecnia, v.38, n.1, p.3439, 2009.

RIBEIRO JR., J.I. Análises estatísticas no SAEG (Sistema para análises estatísticas). Viçosa, MG: Universidade Federal de Viçosa, 2001. 301p.

RIBEIRO, S.D.A. Caprinocultura: criação racional de caprinos. Nobel: São Paulo, 1998. 320p.

SILVA, D.J.; QUEIROZ, A.C. Análise de alimentos: métodos químicos e biológicos. 3.ed. Viçosa, MG: Imprensa Universitária, 2002. 235p.

SILVA, H.G.O. Utilização do farelo de cacau (Theobroma cacao L.) e da torta de dendê (Elaeis guineensis, Jacq.) na alimentação de cabras em lactação. 2003. 77f. Dissertação (Mestrado em Agronomia) - Universidade Estadual do Sudoeste da Bahia, Vitória da Conquista.

SILVA, H.G.O.; PIRES, A.J.V.; SILVA, F.F. et al. Farelo de cacau (Theobroma cacao L.) e torta de dendê (Elaeis guineensis, Jacq.) na alimentação de cabras em lactação: consumo e produção de leite. Revista Brasileira de Zootecnia, v.34, n.5, p.1786-1794, 2005

SILVA, J.H.V.; RODRIGUES, M.T.; CAMPOS, J. Desempenho de cabras leiteiras recebendo dietas com diferentes relações volumoso:concentrado. Revista Brasileira de Zootecnia, v.28, n.6, p.1412-1418, 1999.

SILVA, L.D.F.; EZEQUIEL, J.M.B.; AZEVEDO, P.S. et al. Digestão total e parcial de alguns componentes de dietas contendo diferentes níveis de casca de soja e fonte de nitrogênio, em bovinos. Revista Brasileira de Zootecnia, v.31, n.3, p.1258-1268, 2002.

SKLAN, D.; ASHKENAZI, R.; BRAUN, A. et al. Fatty acids, calcium soaps of fatty acids and cottonseends feed to high yielding cows. Journal of Dairy Science, v.75, n.9, p.2463-2472, 1992.

SNIFFEN, C.J.; O'CONNOR, J.D.; VAN SOEST, P.J. et al. A net carbohydrate and protein system for evaluating cattle diets: II. Carbohydrate and protein availability. Journal of Animal Science, v.70, n.11, p.3562-3577, 1992.

SOUSA, F.G. Níveis crescentes de farelo de cacau (Theobroma cacao L.) na alimentação de ovinos. 2005. 58f. Dissertação (Mestrado em Zootecnia) - Universidade Estadual do Sudoeste da Bahia, Itapetinga.

SOUZA, A.L.; GARCIA, R.; PEREIRA, O.G. et al. Composição químico-bromatológica da casca de café tratada com amônia anidra e sulfeto de sódio. Revista Brasileira de Zootecnia, v.30, n.3, p.983-992, 2001 (supl. 1).

VAN SOEST, P.J. Nutritional ecology of the ruminants. 2.ed. Ithaca: Cornell University Press, 1994. 476p.

WEISS, W.P. Energy prediction equations for ruminant feeds. In: CORNELL NUTRITION CONFERENCE FOR FEED MANUFACTURERS, 61. 1999, Ithaca. Proceedings... Ithaca: Cornell University, 1999. p.176-185. 